\title{
Phyto-Engineered Gold Nanoparticles (AuNPs) with Potential Antibacterial, Antioxidant, and Wound Healing Activities Under in vitro and in vivo Conditions
}

This article was published in the following Dove Press journal:

International Journal of Nanomedicine

\begin{abstract}
Pandi Boomi, (iD)' Ramalingam
Ganesan, ${ }^{2}$ Gurumallesh Prabu

Poorani, ${ }^{3}$ Sonamuthu

Jegatheeswaran, ${ }^{4}$ Chandrasekaran

Balakumar, (iD ${ }^{5}$ Halliah Gurumallesh

Prabu, $^{6}$ Krishnan Anand, ${ }^{7}$

Narayanasamy Marimuthu Prabhu, ${ }^{8}$

Jeyaraman Jeyakanthan,'

Muthupandian Saravanan (iD ${ }^{9}$

'Department of Bioinformatics, Alagappa University, Karaikudi, Tamil Nadu, India;

${ }^{2}$ Department of Chemistry, Arumugam

Seethaiyammal Arts and Science College,

Tiruppattur, Tamil Nadu, India; ${ }^{3}$ Kumaraguru

College of Technology, Coimbatore, Tamil

Nadu, India; ${ }^{4}$ The Key Laboratory of

Advanced Textile Materials and

Manufacturing Technology of Ministry of

Education, College of Materials and Textile,

Zhejiang Sci-Tech University, Hangzhou,

People's Republic of China; ${ }^{5}$ Faculty of

Pharmacy, Philadelphia University, Amman,

Jordan; ${ }^{6}$ Department of Industrial

Chemistry, School of Chemical Sciences,

Alagappa University, Karaikudi, Tamil Nadu,

India; ${ }^{7}$ Department of Chemical Pathology,

School of Pathology, Faculty of Health

Sciences and National Health Laboratory

Service, University of the Free State,

Bloemfontein, South Africa; ${ }^{8}$ Disease

Control and Prevention Lab, Department of

Animal Health and Management, Science

Campus, Alagappa University, Karaikudi,

Tamil Nadu, India; ${ }^{9}$ Department of Medical

Microbiology and Immunology, Division of

Biomedical Sciences, School of Medicine,

College of Health Science, Mekelle

University, Mekelle, Ethiopia
\end{abstract}

Correspondence: Pandi Boomi;

Muthupandian Saravanan

Email pboomi1983@gmail.com;

saravanan.muthupandian@mu.edu.et
Background: A diabetic ulcer is one of the major causes of illness among diabetic patients that involves severe and intractable complications associated with diabetic wounds. Hence, a suitable wound-healing agent is urgently needed at this juncture. Greener nanotechnology is a very promising and emerging technology currently employed for the development of alternative medicines. Plant-mediated synthesis of metal nanoparticles has been intensively investigated and regarded as an alternative strategy for overcoming various diseases and their secondary complications like microbial infections. Hence, we are interested in developing phyto-engineered gold nanoparticles as useful therapeutic agents for the treatment of infectious diseases and wounds effectively.

Methods and Results: We have synthesized phyto-engineered gold nanoparticles from the aqueous extract of Acalypha indica and characterized using advanced bio-analytical techniques. The surface plasmon resonance feature and crystalline behavior of gold nanoparticles were revealed by ultraviolet-visible spectroscopy and X-ray diffraction, respectively. High-performance liquid chromatography analysis of the extract demonstrated the presence of different constituents, while major functional groups were interpreted by the Fourier-transform infrared spectroscopy as the various stretching vibrations appeared for important $\mathrm{O}-\mathrm{H}\left(3443 \mathrm{~cm}^{-1}\right), \mathrm{C}=\mathrm{O}\left(1644 \mathrm{~cm}^{-1}\right)$ and C-O $\left(1395 \mathrm{~cm}^{-1}\right)$ groups. Scanning electron microscopy, high-resolution transmission electron microscopy results revealed a distribution of spherical and rod-like nanostructures with $20 \mathrm{~nm}$ of size. The gold nanoparticle-coated cotton fabric was evaluated for the antibacterial activity against Staphylococcus epidermidis and Escherichia coli bacterial strains which revealed remarkable inhibition at the zone of inhibition of $31 \mathrm{~mm}$ diameter against $S$. epidermidis. Further, antioxidant activity was tested for their free radical scavenging property, and the maximum antioxidant activity of the extract containing gold nanoparticles was found to be $80 \%$ at $100 \mu \mathrm{g} / \mathrm{mL}$. The potent free radical scavenging property of the nanoparticles is observed at $\mathrm{IC}_{50}$ value $16.25 \mu \mathrm{g} / \mathrm{mL}$. Moreover, in vivo wound-healing activity was carried out using BALB/c mice model with infected diabetic wounds and observed the stained microscopic images at different time intervals (day 2, day 7 and day 15). It was noted that in 15 days, the wound area is completely re-epithelialized due to the presence of different morphologies such as spherical, needle and triangle nanoparticles. The reepithelialization layer is fully covered by nanoparticles on the wound area and also collagen filled in the scar tissue when compared with the control group.

Conclusion: The pharmacological evaluation results of the study indicated an encouraging antibacterial and antioxidant activity of the greener synthesized gold nanoparticles tethered with aqueous extract of Acalypha indica. Moreover, we demonstrated enhanced in vivo wound-healing efficiency of the synthesized gold nanoparticles through the animal model. Thus, the outcome of 
this work revealed that the phyto-engineered gold nanoparticles could be useful for biomedical applications, especially in the development of promising antibacterial and wound-healing agents.

Keywords: gold nanoparticles, antibacterial, antioxidant, wound healing, in vivo mice model

\section{Introduction}

Infectious diseases caused by different microorganisms are currently the life-threatening clinical challenges, globally. ${ }^{1}$ Wound management remains one of the clinical problems in healthcare which can lead to severe infections resulting in increased morbidity and mortality. When human skin is damaged, microorganisms can easily penetrate underlying tissues and subsequently generate the wound infection. ${ }^{2}$ To control the microorganism growth within wound infection, several metal nanoparticles (MNPs) have been synthesized by chemical methods which provide various advantages such as high purity, desired shape, and structure. ${ }^{3,4}$ Nevertheless, they suffer from major obstacles such as high cost, hazards to health, or possibly unsafe to the environment. Therefore, an effective treatment strategy is very essential for the management of wound infection. Greener nanotechnology is well recognized to overcome various drawbacks associated with the chemical methods. The technology can also help to improve the efficacy of different therapeutics. MNPs tethered plant parts have emerged as feasible options to reduce bacterial infections and increase wound-healing processes. ${ }^{5}$ The MNPs are having much greater physiochemical properties such as electronic, optical, magnetic, mechanical, and catalysis due to their lower particle size, surface plasmon resonance, surface area, effect of particle shape, structural morphology, effective surface charge, and crystalline structure. ${ }^{6-8}$ Considering unique properties, they are widely explored for their variety of potential therapeutic applications like antibacterial, antioxidant, anticancer, wound-healing agents, imaging and targeted drug delivery. ${ }^{9-13}$

Natural plant sources are gaining vast attention, which can be effectively employed in the preparation of MNPs owing to their easier availability, less toxic behavior and cost-effectiveness. ${ }^{14,15}$ The synthesis of MNPs conjugated to various plants such as Cladophora fascicularis, ${ }^{16}$ Pinus pinaster, ${ }^{17}$ Aerva lanata, ${ }^{18}$ Artemisia annua,${ }^{19}$ Hippophae rhamnoides Linn, ${ }^{20}$ Eucommia ulmoides, ${ }^{21}$ black tea leaf, ${ }^{22}$ Averrhoa bilimbi, ${ }^{23}$ Salicornia brachiata, ${ }^{24}$ Abelmoschus esculentus $\mathrm{L},{ }^{25}$ olive leaf, ${ }^{26}$ Ipomoea carnea, ${ }^{27}$ geranium, ${ }^{28}$ and Cissus arnotiana ${ }^{29}$ have been documented. Among various types of nanoparticles, gold nanoparticles (AuNPs) have gained greater attraction in antibacterial, antioxidant and wound-healing applications when combined with natural phytoconstituents. ${ }^{30-32}$ Insulin plant Chamaecostus cuspidatus mediated AuNPs have restored the normal blood glucose, glycogen, and insulin levels by evaluating in vivo woundhealing activity. ${ }^{33}$ Arafa et al prepared two transdermal formulations as thermo-responsive gels bearing AuNPs and evaluated in vitro antibacterial activity against Staphylococcus aureus (mostly found in burn infections) using a model of burn-induced infected wounds in mice. The developed formulations demonstrated antibacterial activity with promising wound-healing properties based on in vivo and histopathological studies. ${ }^{34}$ Hajialyani et al reviewed various natural products-based nanomedicines for wound healing, emphasizing mainly on drug delivery systems. They presented various studies on green synthesized MNPs using aqueous extract of 12 different plant materials and some phytoconstituents such as curcumin, emodin, dihydroquercetin, and centella. ${ }^{35}$ More recently, Mihai et al, amongst others, synthesized copper NPs from leaf extract of Falcaria vulgaris and determined the cytotoxicity, antibacterial, antifungal, antioxidant and cutaneous wound-healing activities. ${ }^{36}$ Further, the same research group prepared silver NPs using aqueous extract of Allium saralicum and evaluated for biological activity against a panel of bacterial and fungal strains and documented promising inhibition profiles. $^{37-39}$

Functionally modified textiles are receiving greater attention and significant growth due to the wide awareness in case of hygiene and health considerations. Particularly, fabrics bearing antibacterial properties can offer synergistic and dual beneficial effects to the textiles. ${ }^{40-44}$ Nanoparticles amalgamated with modified cotton fabrics, conferred an extensive antibacterial activity and well-balanced laundering durability. ${ }^{45}$ This is principally mediated through the binding of MNPs into the surface of the fabrics by forming electrostatic forces or coordinating interactions between MNPs and co-ordinating groups. ${ }^{46}$ The antimicrobial function of different MNPs has been recognized for several other purposes such as textile, cosmetics, and food processing, etc. ${ }^{47}$ Besides, the AuNPs have been utilized to develop the accelerated wound healing by activating different healing phases. ${ }^{48}$ The AuNPs-coated cotton fabrics 
exhibit improved recovery action when compared with positive drug-treated group. ${ }^{49}$

Acalypha indica is a common weed plant that occurs throughout tropical Africa, South East Asia, India, Indian Ocean Islands, Sri Lanka, Yemen, and Pakistan. This plant belongs to the family Euphorbiaceae and genus Acalypha.$^{50}$ It is a well-known traditional herbal medicinal plant which is easily distributed and identified in most agricultural lands, gardens and uncultivated lands. Acalypha indica was employed as a traditional herbal medicine for the treatment of various respiratory tract diseases such as bronchitis, asthma, and pneumonia. Leaves of the plant exhibited antiparasitic action, and the decoction of the leaf is used for the management of ear pain. ${ }^{51}$ Several possible natural bioactive compounds such as acalyphine, triacetoneamine, cyanogenic glucosides, alkaloids, flavonoids, catechols, saponins, volatile oil, fatty acids, etc., are present in all parts of Acalypha indica. ${ }^{50}$ They provide diversified medical applications, including anti-inflammatory and antimicrobial properties. ${ }^{52}$ Hence, the literature well documented the medicinal significance of Acalypha indica, which motivated us to select this particular herb and to be taken further for investigating the potential antibacterial, antioxidant, and wound-healing properties.

In continuation of our research efforts in acquiring greener synthesis of AuNPs, and beneficial effects of the natural herb Acalypha indica are synergized to enhance the biocompatibility and efficiency of fabrics. Further, our study is aimed to investigate the potential antibacterial properties of AuNPs on cotton fabric using a simple anchoring procedure. Moreover, our study motivated us to evaluate its antioxidant activity and in vivo woundhealing properties using a suitable animal model.

\section{Experimental \\ Materials and Methods}

The woven cotton fabric of 80 counts was obtained from The South Indian Textile Research Association (SITRA), Coimbatore, India. Fresh leaves of Acalypha indica were collected from the agricultural lands (Latitude: $10^{\circ} 04^{\prime}$ 12.00" N, Longitude: $78^{\circ} 46^{\prime} 48.00^{\prime \prime}$ E) available in the local area of Karaikudi, Tamil Nadu, India. The plant was identified from Department of Botany, Alagappa University, Karaikudi, India and the plant's specimen repository serial number is ALUDB-3020589. Chloroauric acid $\left(\mathrm{HAuCl}_{4} \cdot 3 \mathrm{H}_{2} \mathrm{O}\right)$ and dimethyl sulphoxide (DMSO) were procured from Sigma Aldrich and used without any further purification. Buffer tablets of specific $\mathrm{pH}$ were purchased from Ranbaxy, India and used as such. Highly purified water was generated from the TKA-LAB Reinst water system. Bacterial strains of Staphylococcus epidermidis (S. epidermidis; ATCC 35984) and Escherichia coli (E. coli; ATCC 10546) were used for antibacterial activity are received from the Department of Biotechnology, Alagappa University, India.

\section{Preparation of Acalypha indica Leaf Extract} Acalypha indica leaf extract was prepared by continuous hot extraction at a temperature of $100^{\circ} \mathrm{C}$. For the extraction, $30 \mathrm{~g}$ of cleaned leaves were completely triturated with $90 \mathrm{~mL}$ water. This mixture is subjected to continuous hot extraction for 15 min using a Soxhlet apparatus and filtered accordingly. The filtrate, thus obtained by this method, was used as a reducing agent for the synthesis of AuNPs.

\section{Green Synthesis of AuNPs}

An equal quantity of Acalypha indica leaf extract $(2.5 \mathrm{~mL})$ and $0.001 \mathrm{M}$ of $\mathrm{HAuCl}_{4} .3 \mathrm{H}_{2} \mathrm{O}(2.5 \mathrm{~mL})$ with $1 \mathrm{~mL}$ of buffer solution $(\mathrm{pH} \mathrm{7)}$ were taken in an Erlenmeyer flask. With the help of a magnetic stirrer, the reaction mixture was stirred at $240 \mathrm{rpm}$. The reduction step of $\mathrm{Au}^{3+}$ ions to AuNPs was attained and subsequently tracked by the change in the color of the mixture from light to dark brown. This protocol was further extrapolated using a high concentration of chloroauric acid $(0.01 \mathrm{M})$ to gain an insight into the effect of concentration on green synthesis.

\section{Pre-Treatment of Cotton}

In order to eliminate various impurities occurring in the fabric, the cotton fabric was suitably pre-treated (scouring and bleaching) using a one-pot mechanism. Specifically, $\mathrm{HCl}(0.4 \mathrm{~mL}), \mathrm{NaOH}$ (1.9 g), $\mathrm{Na}_{2} \mathrm{CO}_{3}$ (3.9 g) and $\mathrm{H}_{2} \mathrm{O}_{2}$ $(1.9 \mathrm{~mL})$ were assorted in distilled water $(200 \mathrm{~mL})$. The fabric was subsequently buried in the bath, and the constant temperature of $80^{\circ} \mathrm{C}$ was maintained for about 90 min. Then, the pre-treated fabric was removed, washed with a sufficient quantity of water and adequately dried. Finally, the dried fabric was used as such, subsequently for further steps.

\section{Coating on Cotton Fabric}

The intact extract was appropriately coated with the cotton fabric employing pad-dry-cure procedure. The fabric was 
stuffed into a padding mangle consisting of Acalypha indica leaf extract $(100 \mathrm{~mL})$ and the padding operation was accomplished at ambient conditions for 15 mins. Finally, the coated fabric was detached, washed with water and adequately dried under air. Similarly, the coating process was followed by the extract comprising AuNPs as well. $^{53}$

\section{Characterization of Synthesized AuNPs by Instrumentation}

The synthesized AuNPs were characterized by employing UV-vis spectrophotometer (Jasco-V-530) and consequently observed various surface plasmon resonance (SPR) peaks. The powdered extract containing AuNPs was characterized by X'Pert PRO XRD equipment to understand the crystalline nature. Possible phytochemicals containing varied functionality were identified by HPLC (Shimadzu), Detector SPD 10A; Pump LC-8A; Silicon C18 column Phenomenez (Shimadzu). FT-IR spectra were recorded to identify the functional group using BRUKER Optik GmbH - TENSOR 27. The surface coating morphology of the fabric and the shape of AuNPs were investigated by applying HITACHI S3000H SEM at $15 \mathrm{kV}$. In addition, the particle size of AuNPs was analyzed with the help of a high-resolution transmission electron microscope (HRTEM) JEOL-JEM 2100 working at $200 \mathrm{kV}$.

\section{In vitro Antibacterial Evaluation}

The free uncoated cotton, pristine extract-coated cotton and the extract consisting of AuNPs-coated cotton fabrics were evaluated for their antibacterial actions against $S$. epidermidis (Gram-positive) and E. coli (Gram-negative) strains, respectively. The antibacterial activity was measured by disc diffusion susceptibility assay in the MHA medium. The strains were grown in Luria Bertani (LB) broth and tryptic soy broth (TSB) and subsequently incubated at a temperature of $37^{\circ} \mathrm{C}$. For all the antibacterial assays, overnight cultures of both bacterial strains were used in 1:100 dilutions and sub-cultured in the same broth till turbidity of 0.5 McFarland standard $\left(1 \times 10^{8} \mathrm{CFU}\right.$ $\mathrm{mL}^{-1}$ ) was attained. The cultures were evenly dispersed onto the agar plate surface by employing a sterile cotton swab and left it for 10 min to confer the absorption of any excess of moisture. In the swabbed plate, $1.5 \times 1.5 \mathrm{~cm}$ size of each of the different cotton fabrics was placed on LBA plates and incubated at a temperature of $37^{\circ} \mathrm{C}$. After $24 \mathrm{~h}$, the plates were examined and measured the zone of inhibition (ZOI) subsequently. ${ }^{54}$

\section{In vitro Evaluation of the Antioxidant Activity}

The antioxidant activity of the extract containing AuNPs was examined by DPPH free radical scavenging assay according to the standard protocols. ${ }^{55}$ In this method, the DPPH solution $(0.1 \mathrm{mM})$ was prepared by using methanol and absorbance was recorded at $517 \mathrm{~nm}$ using a microplate reader. The DPPH solution $(100 \mu \mathrm{g} / \mathrm{mL})$ was mixed with 3 $\mathrm{mL}$ of extract containing AuNPs solution and incubated for $30 \mathrm{~min}$. The discoloration of purple color was noticed and recorded at $517 \mathrm{~nm}$. Methanol was used as blank, whereas DPPH in methanol with the ascorbic acid solution $(0.05-0.3 \mathrm{mg} / \mathrm{mL})$ was used as a standard which served as a positive control. The percentage of the free radical scavenger was calculated using the following equation:-

$$
\% \text { DPPH scavenge }=\left(A_{c}-A_{t} / A_{c}\right) \times 100
$$

where $A_{c}$ and $A_{t}$ are the absorbance of the control and test samples, respectively.

\section{In vivo Evaluation of the Wound-Healing Activity}

The in vivo wound-healing activity was determined by using BALB/c mice, according to the approved protocols of International Animal Experiment Procedure, Zhejiang Sci-Tech University, China. For this in vivo wound-healing analysis, the animal model was procured and performed experimentally according to the standard guidelines for care and use of laboratory animals of National Institute of Health, China. The experimental protocol was followed according to the previously reported article. ${ }^{56}$ In brief, streptozotocin was injected to an intraabdominal place of BALB/c mice at a dose of $75 \mathrm{mg} / \mathrm{kg}$ to create diabetes mellitus. After 2 days, the blood glucose levels were monitored by using Glucometer and the glucose level of $21.3 \mathrm{mmol} / \mathrm{L}$ was noticed. Every day for 4 weeks, 1-2.5 units of insulin are administered to all diabetic-induced models with a suitable diet to keep higher blood glucose levels to prevent acute crisis problems. After 4 days, the blood glucose level was reached to $23.1 \mathrm{mmol} / \mathrm{L}$. Then, the animals were anaesthetized under the appropriate dosage of ketamine (anesthetic drug), and the wound $(20 \mathrm{~mm}$ ) was created on the dorsal midline by using an electric shaver and cleaned with $70 \%$ 
alcohol. All the wounds of each animal were arbitrarily treated to control. The extract containing AuNPs was applied to the wound spot using a syringe. With the help of the glass rod, the applied material was speared on the whole wound surface area and covered with a surgical bandage. For the control animals, the surgical bandage was covered with adhesive bandage. All animals were kept in separate cages at ambient temperature. The wound size reduction diameter was measured and photographed regularly in days 3, 7 and 15 .

\section{Histopathological Analysis}

The histopathological analysis was conducted using two staining procedures such as hematoxylin eosin (H\&E) and Masson's trichrome (MT). The experimental procedure followed for this analysis is similar as per our recently published work ${ }^{57}$, which explored the inflammatory infiltration, collagen and fibroblast formations, neovascularization under standard protocols. The improved diabetic wound-healing closure rate was calculated from the following equation:

Wound closurearea $($ WA $\%)=($ WAs - WAt $) /$ WAs $\times 100$

where: WAs is the value of the original wound area in the surgery day and WAt is the value of the healed wound area at a specified time point.

\section{Results and Discussion}

The reduction process of $\mathrm{Au}^{3+}$ ions to AuNPs was monitored based on the color change of the reaction mixture from light brown to dark brown. The reaction mixture color began to change after $5 \mathrm{~min}$, which indicated the subsequent reduction of chloroauric acid into gold particles. Further, sophisticated instrumental analytical techniques such as UV-visible spectroscopy, XRD, HPLC, FTIR, FE-SEM with EDA, HR-TEM with SAD analysis, and SEM with EDAX analysis were employed for the complete characterization. Moreover, the material was evaluated for antibacterial, antioxidant and wound-healing properties.

\section{UV-Vis Analysis}

UV-visible spectroscopy can be used to examine the formation of AuNPs with their surface plasmon resonance (SPR peaks) and shape. Figure 1 presents UV-visible spectra of the pure extract (curve A in black colour) and extract composed of AuNPs (curve B in pink colour) deduced from the $0.001 \mathrm{M}$ concentration of chloroauric

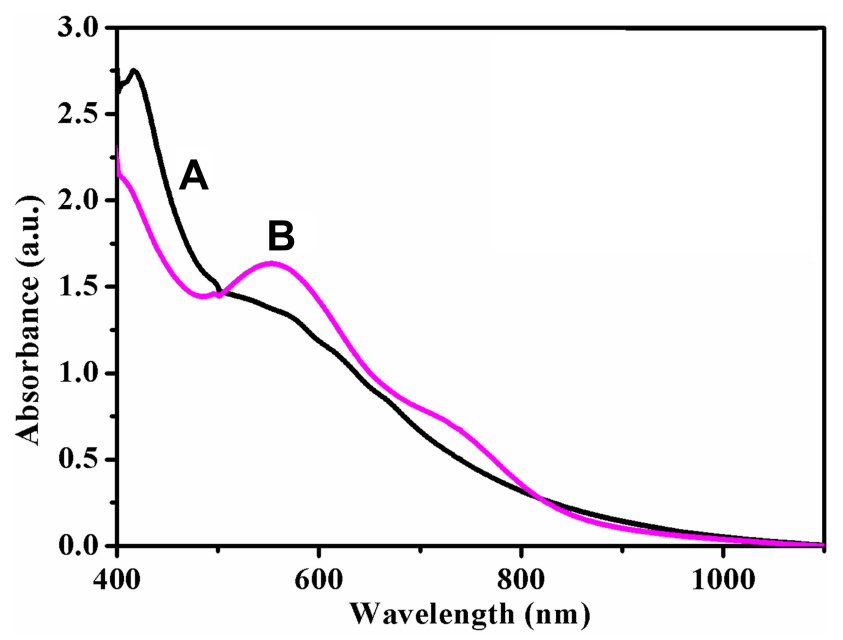

Figure I UV-vis absorption spectra of Neat Acalypha indica leaf extract (curve $A$ in black colour) and AuNPs synthesized from Acalypha indica (curve B in pink colour). Abbreviations: AuNPs, gold nanoparticles; UV-vis, ultraviolet-visible.

acid. The reaction was monitored by UV-visible spectrophotometer till the end of $1 \mathrm{~h}$, and the perfect sharp band was observed at $552 \mathrm{~nm}$, which was attributable to SPR of AuNPs (curve B). ${ }^{44}$ The formation of the SPR band may be due to the shape and size during the production of AuNPs $^{58,59}$ which can be further confirmed by the formation of spherical and rod-like shapes of AuNPs. This may be due to the attainment of saturation in the bio-reduction of $\mathrm{Au}^{3+}$. In general, the intensity of the SPR peak has a positive correlation with the reduction of gold ions to AuNPs. The formation of stable dark purple color in the reaction mixture demonstrated the complete reduction of gold ions to AuNPs. Further an extension of the stirring time (maximum of $1 \mathrm{~h}$ ) resulted in no noticeable changes in the absorbance pattern. The leaf extract did not exhibit any absorption peak on electronic spectra (curve A).

\section{XRD Analysis}

XRD analysis is carried out to study the crystalline structure of greener synthesized metal NPs. Neat extract and the extract containing AuNPs were subjected to XRD analysis. The XRD patterns of neat extract, AuNPs synthesized at $0.001 \mathrm{M}$ concentration precursor are shown in Figure $2 \mathrm{~A}$ and $\mathrm{B}$. The patterns are employed to confirm the crystalline nature of the metal particles. Figure $2 \mathrm{~A}$ shown no corresponding peaks of Au metal in the leaf extract. Figure 2B exhibits numerous Bragg reflection peaks obtained at $38^{\circ}, 44^{\circ}, 64^{\circ}$ and $77^{\circ}$ which are indexed by planes (111), (200), (220) and (311), respectively, on the basis of the face-centred cubic orientation of $\mathrm{Au}^{32}$ The 


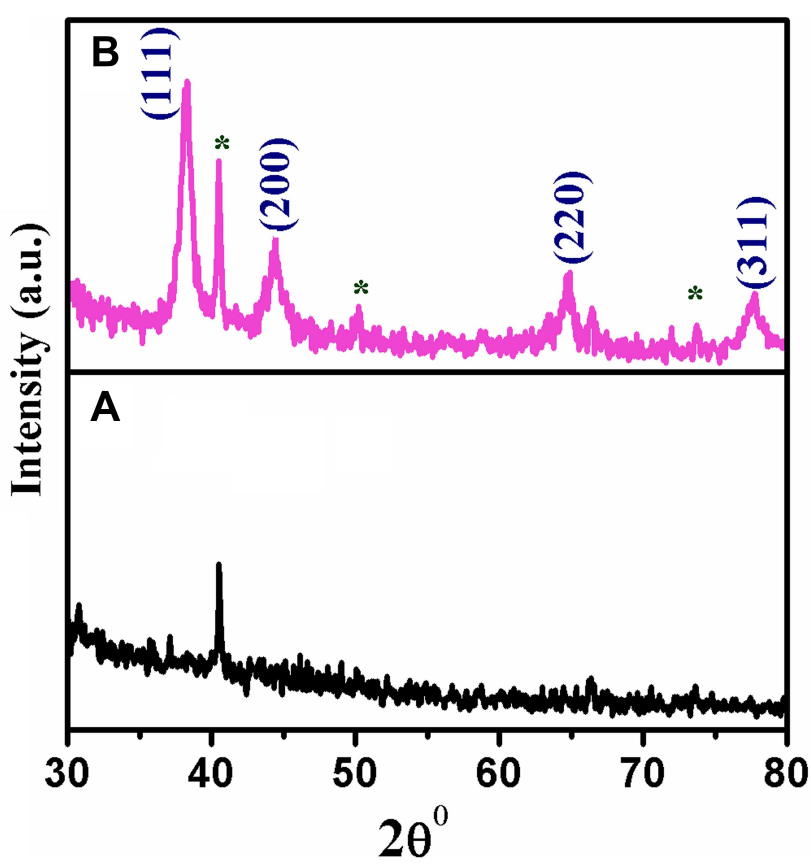

Figure 2 XRD patterns of (A) Neat Acalypha indica leaf extract and (B) AuNPs synthesized from Acalypha indica. (* Bioinorganic constituents present in the extract). Abbreviations: XRD, X-ray diffraction; AuNPs, gold nanoparticles

obtained peak lists are identical with the reported data of the standard gold metal by the Joint Committee on Powder Diffraction Standards (JCPDS) [File No. 01-089-3697].

The average size of AuNPs is calculated using the Scherrer formula. The (111) plane of the synthesized AuNPs is observed more intensely than other planes. Therefore, the (111) plane of the AuNPs is used to calculate the particle size of the Scherrer equation as $19 \mathrm{~nm}$.
The particle size obtained through XRD analysis is further corroborated by the particle size determined from the HRTEM. $^{44}$.

\section{HPLC Analysis}

All possible individual constituents of the extract are identified under optimized wavelength $(340 \mathrm{~nm})$ and depict the HPLC chromatogram corresponding to their retention time (Figure 3). UV-vis analysis of a greencoloured neat extract of Acalypha indica leaf showed different peaks at 275, 340,369, 449, 564 and $601 \mathrm{~nm}$. A peak at $340 \mathrm{~nm}$ is observed to be more significant and is considered for further HPLC analysis to recognize the presence of major phytoconstituents in the neat extract. The UV spectrum of the extract of Acalypha indica leaf is displayed in inset Figure 3A.

Based on the presence of the number and quantity of individual phytoconstituents in the extract, minor and major peaks are obtained. Table 1 represents various peaks attributable to seven different phytoconstituents and their corresponding retention time. The identification of various phytoconstituents present in the plant extracts is mainly based on the comparison of retention time reported in the literature. The identified compounds may have one or more similar or different functional groups, as listed in Table 1.

The compound numbers 1, 2, 4 and 7 have active carbonyl functional groups that suggest a complete reduction of $\mathrm{Au}^{3+}$ ions to AuNPs. These referred compounds are

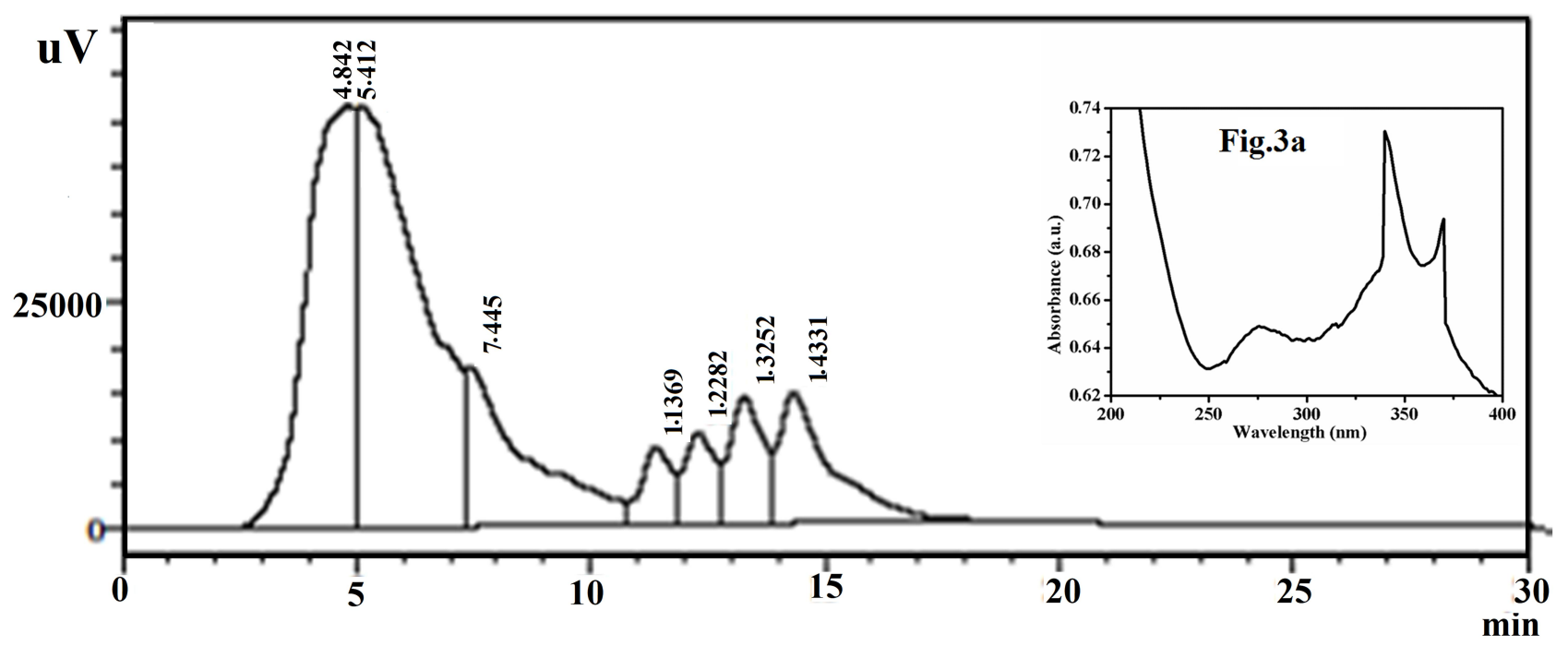

Figure 3 HPLC chromatogram profile of aqueous extract of Acalypha indica leaf at $340 \mathrm{~nm}$; UV spectrum of aqueous Acalypha indica leaf extract (Inset Figure $3 \mathrm{~A}$ ). Abbreviations: HPLC, high-performance liquid chromatography; UV, ultraviolet. 
Table I Retention Time of Phytochemicals Present in the Acalypha indica Leaf Extract Observed at $340 \mathrm{~nm}$

\begin{tabular}{|l|l|l|l|l|l|}
\hline Compound No. & $\begin{array}{l}\text { Retention Time } \\
\text { (min) }\end{array}$ & Area \% & Height \% & Compound Identified & Number of Carbonyl Groups \\
\hline 1 & 4.842 & 28.454 & 29.694 & Sildenafil citrate & 4 \\
2 & 5.142 & $35.95 I$ & 29.385 & Geniposidic acid & 1 \\
3 & 7.445 & 13.334 & 11.139 & 3,5 -dimethylphenol & - \\
4 & 11.369 & 3.182 & 5.378 & Palmitic acid & 1 \\
5 & 12.282 & 3.775 & 6.407 & Borneol & - \\
6 & 13.252 & 5.776 & 8.932 & 2-Hexyl-I-octanol & - \\
7 & 14.331 & 9.528 & 9.065 & $\alpha$-Terpinyl acetate & 1 \\
\hline
\end{tabular}

concurred with FT-IR stretching frequency noticed at $1664 \mathrm{~cm}^{-1}$ for carbonyl derivatives called amide-I (functional group). Therefore, these four compounds may be involved in the reduction of gold ions rather than other compounds (numbers 3, 5 and 6). ${ }^{57,60-62}$

The HPLC chromatogram also revealed that the percentage content of each identified compound is present in the extract. The high total percentage of carbonyl compounds is noticed as $77.115 \%$, which is a higher percentage than compounds lacking carbonyl fragments $(22.885 \%)$. The peak area or peak percentage suggested the concentration of the compounds present in the extract. In this regard, compounds 1 and 2 are identified in higher percentage content. Out of these two compounds, the compound number 1 may be dominated by the reduction reaction; even it has less content of carbonyl group than compound 2. This may be due to the presence of an amide functional group, which was further confirmed by FT-IR analysis.

\section{FT-IR Analysis}

The neat extract and the extract containing AuNPs were subjected to FT-IR spectroscopy to identify the possible functional groups, including the active carbonyl $(\mathrm{C}=\mathrm{O})$ moiety in the Acalypha indica leaf extract. The individual FT-IR spectrum of the leaf extract and reaction mixture obtained by $0.001 \mathrm{M}$ concentration precursors are shown in Figure 4A and B.

The leaf extract (Figure 4A) shows the strong bands at 3443, 1644, 1395, 1064 and $601 \mathrm{~cm}^{-1}$. The broadband appeared at $3443 \mathrm{~cm}^{-1}$ is assigned to $\mathrm{O}-\mathrm{H}$ group stretching vibration. A prominent band presented at $1644 \mathrm{~cm}^{-1}$ is ascribed to the stretching vibration of the amide- $\mathrm{I}(\mathrm{C}=\mathrm{O})$ group of proteins that occurred in the extract. ${ }^{63,64}$ The band appeared at $1395 \mathrm{~cm}^{-1}$ is distinctive of C-O stretching of carboxylic functionality. ${ }^{65}$ The bands at $1064 \mathrm{~cm}^{-1}$ and $601 \mathrm{~cm}^{-1}$ are characteristic of C-N stretching mode in primary amine and $\mathrm{C}-\mathrm{S}$ stretching mode in disulphide groups, respectively.

The extract containing AuNPs exhibits the peaks for diversified functional groups at 3510, 1750, 1125 and $700 \mathrm{~cm}^{-1}$ (Figure 4B). All the mentioned peaks are shifted to higher wavenumbers. The difference in the peak and a small shift in the band position is observed in curve B which indicates the free amino or carboxylic groups or different bioorganic compounds present in the extract that can bind onto the metal surfaces to stabilize the particles. ${ }^{66,67}$ The Acalypha indica leaf extracts containing amide, phenolic, and carbonyl compounds were reported for the involvement in the reduction of the metal ions. As mentioned earlier,

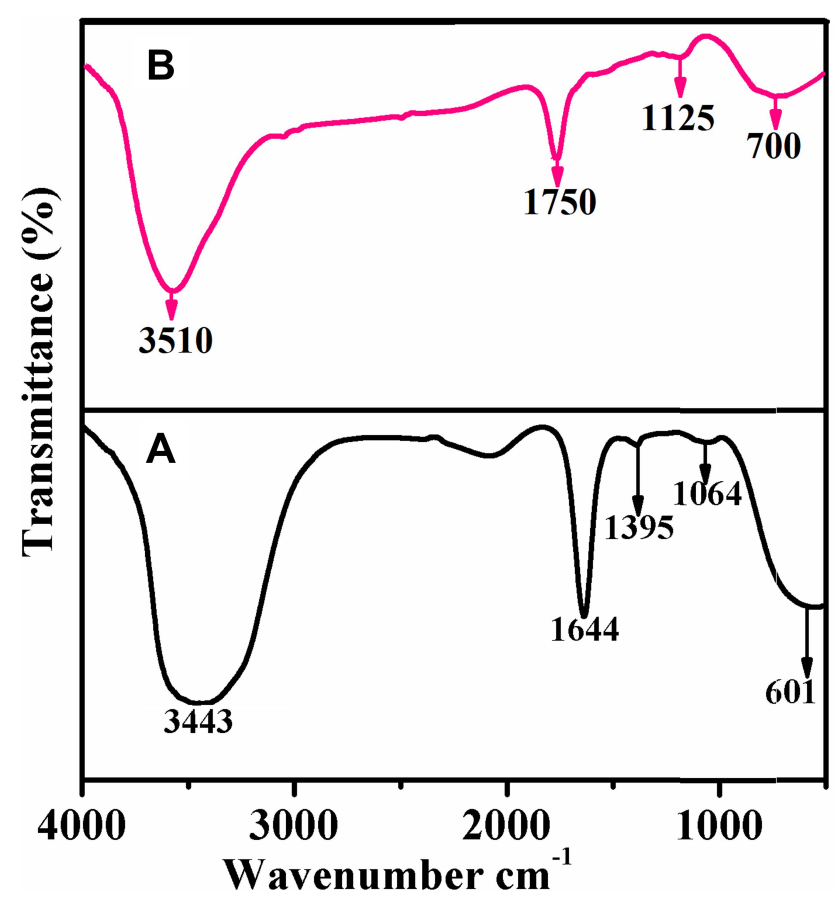

Figure 4 FT-IR spectra of (A) Neat extract and (B) extract containing AuNPs synthesized from Acalypha indica.

Abbreviations: FT-IR, fourier transform-infrared; AuNPs, gold nanoparticles. 
Acalypha indica plants had a variety of phytochemical compounds that are possessing different functional groups such as $\mathrm{O}-\mathrm{H}, \mathrm{C}=\mathrm{O}, \mathrm{C}-\mathrm{N}, \mathrm{C}-\mathrm{S}$ and $\mathrm{C}-\mathrm{O}$ identified from FT-IR analysis. The $\mathrm{OH}$ functional groups may be responsible for the bio-reduction of gold ions to gold nanoparticles. ${ }^{68}$ It was evidenced that the hydroxyl group has the ability to bind and reduce the metal ions to metal nanoparticles and proposed the mechanism of reduction of gold ions to gold nanoparticles (Figure 5).

\section{FE-SEM with EDAX and HR-TEM with SEAD Analyses}

The synthesized AuNPs were analyzed by SEM with EDAX, and the results are illustrated in Figure 6A and B. Figure $6 \mathrm{~A}$ shows a large number of spherical and rodlike morphologies of AuNPs. Moreover, the smaller and higher spherical AuNPs are well dispersed that can be attached to the rod-shaped nanoparticles. Furthermore, to confirm the formation of AuNPs, the EDAX spectrum is used to monitor the elements present in the synthesized compound (Figure 6B). The presence of a strong signal identical to the gold metal is observed in this spectrum. The $\mathrm{Cu}$ peak originates from the copper plate during the preparation of the sample for SEM analysis. In addition to the anticipated peaks, other elemental peaks such as $\mathrm{C}, \mathrm{O}$, $\mathrm{N}, \mathrm{K}, \mathrm{Cl}$ and $\mathrm{Mn}$ are also observed in the spectrum, which may be due to the existence of different phytochemical elements in the Acalypha indica extract.

The structural morphology and crystallinity of the synthesized AuNPs using Acalypha indica leaf extract are further confirmed by HR-TEM with SAED, which are displayed in Figure $6 \mathrm{C}$ and D. The distribution of predominant spherical shape of AuNPs with $20 \mathrm{~nm}$ of size was obtained (Figure 6C). The traces of triangularshaped particles were also observed. In addition, a single spherical lattice spring is obtained as indicated in the inset image. The SAED result (Figure 6D) shows bright circular rings and are associated with (111), (200), (220) and (311) planes of AuNPs. ${ }^{69}$

\section{SEM with EDAX Analysis of AuNPs Coated on Cotton Fabric}

SEM with EDAX images of uncoated, neat extract coated, and AuNPs-coated cotton fabrics are compared in Figure 7A-F. Uncoated cotton fabric shows spirals together or side-by-side layers in a cylindrical structure (Figure $7 \mathrm{~A}$ ). ${ }^{70}$ After loading neat extract on the cotton fabric, the single fibre can be changed to rough morphology (Figure 7C). When the extract containing AuNPs is loaded on the cotton fabric, the smooth morphological structure is fully changed to rough morphology, indicating that AuNPs successfully deposited on the cotton fabric. The AuNPs are evenly attached to the cotton fabric surface by the electrostatic interaction (Figure 7E). Further, the EDAX spectrum (Figure 7B, D, and F) supports the existence of $\mathrm{C}, \mathrm{O}, \mathrm{K}, \mathrm{Mg}, \mathrm{Si}, \mathrm{Cl}, \mathrm{Ca}$ elements and AuNPs on the surface of cotton fabric. ${ }^{40}$

\section{In vitro Antibacterial Evaluation}

Uncoated cotton, extract-coated cotton, and extract containing AuNPs-coated cotton were evaluated for their antibacterial actions against $S$. epidermidis and E. coli, as shown in Figure 8. The antibacterial evaluation was determined by disc diffusion susceptibility assay for $24 \mathrm{~h}$ duration. ${ }^{71}$ The improved zone of inhibition (ZOI) of AuNPs-coated cotton is significantly observed at 24th $\mathrm{h}$ and labelled as 3. Similarly, the ZOI obtained for uncoated and extracted coated cotton is labelled as 1 and 2, respectively. The highest ZOI of bacterial growth is noticed around AuNPs coated with cotton against $S$. epidermidis (31 $\mathrm{mm}$ diameter) than E. coli $(26 \mathrm{~mm}$ diameter). In a parallel way, the maximum ZOI of bacterial growth is observed for extract-coated cotton against $S$. epidermidis (25 mm diameter) rather than E. coli (19 $\mathrm{mm}$ diameter). Both uncoated cotton and extract-coated cotton exhibited good antibacterial activity. Due to the presence of bioactive compounds in the extraction and formation of gold nanoparticles, an improved antibacterial activity was noticed for AuNPs-coated cotton. This is attributable to

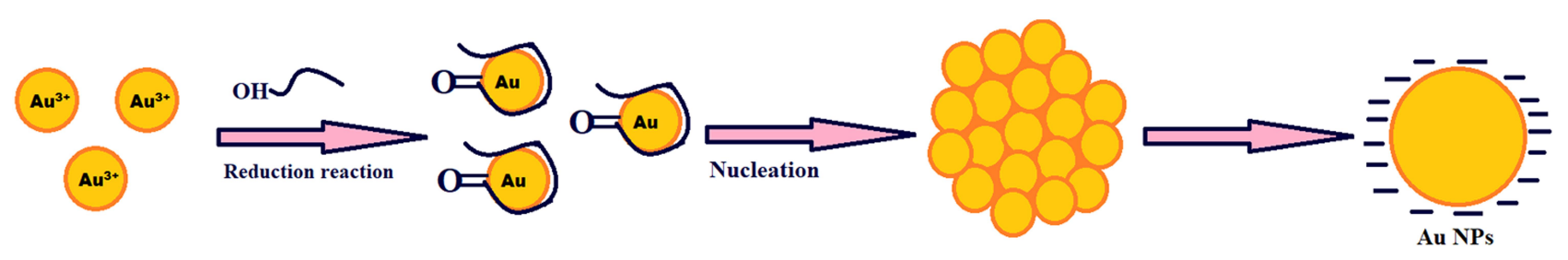

Figure $\mathbf{5}$ The proposed mechanism of reduction of gold ions to gold nanoparticles. 

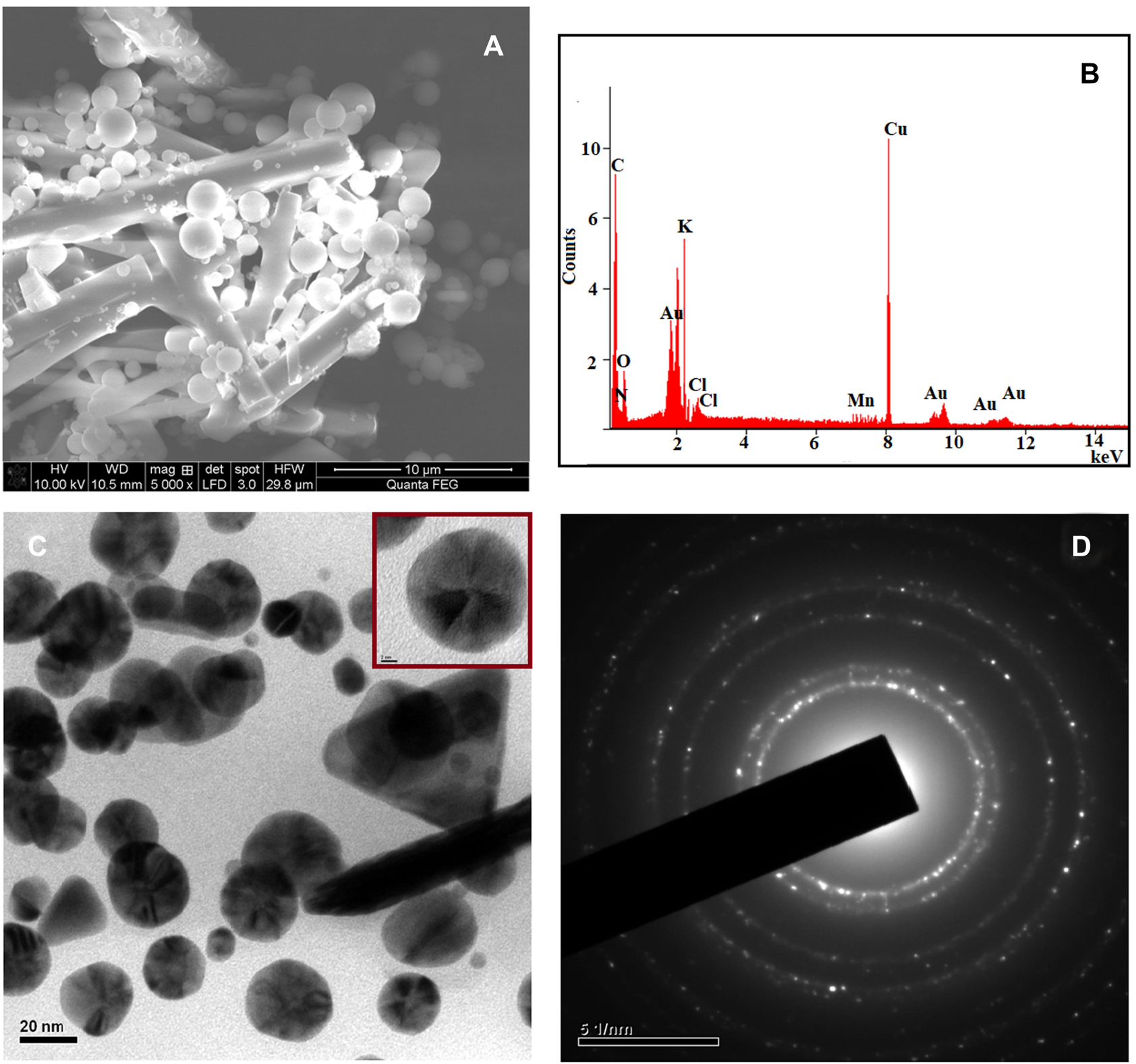

Figure 6 FE-SEM with EDAX images of AuNPs obtained from Acalypha indica (A and B) and HR-TEM with SAED images of AuNPs obtained AuNPs obtained from Acalypha indica (C and D).

Abbreviations: FE-SEM, field emission scanning electron microscope; EDAX, energy dispersive analysis of X-rays; HR-TEM, high-resolution transmission electron microscopy; SAED, selected area electron diffraction; AuNPs, gold nanoparticles.

the existence of AuNPs on the surface of the cotton fabric mediated through the hydroxyl groups present in the extract. $^{72}$

The proposed mechanism of the antibacterial activity of AuNPs against inhibitory effects of microorganisms could be occurred through the electrostatic force of attraction between the nanoparticles and the cell membrane of the corresponding bacterial strains. ${ }^{68}$ Thus, the cotton fabric with immobilized AuNPs without any binder exhibited potential antibacterial activity. The washing stability is also established because of the existence of electrostatic forces and co-ordination links between AuNPs and the amino group present in the extract. ${ }^{46}$ The antibacterial activity result was found to be unique from other studies reported by Zangeneh et al. ${ }^{38,39}$ Authors determined minimum bactericidal concentration (MBC) as an expression of the antibacterial activity of Falcaria vulgaris leaf extract conjugated copper NPs against $E$. coli at the concentration of $8-16 \mu \mathrm{g} / \mathrm{mL}$. Similarly, in another study by the same authors, we reported the maximum ZOI against $E$. coli is $30 \mathrm{~mm}$ for silver NPs obtained using $A$. saralicum aqueous extract. $^{38,39}$ Our study determined the ZOI against E. coli as $26 \mathrm{~mm}$ diameter, which is comparable to ZOI 

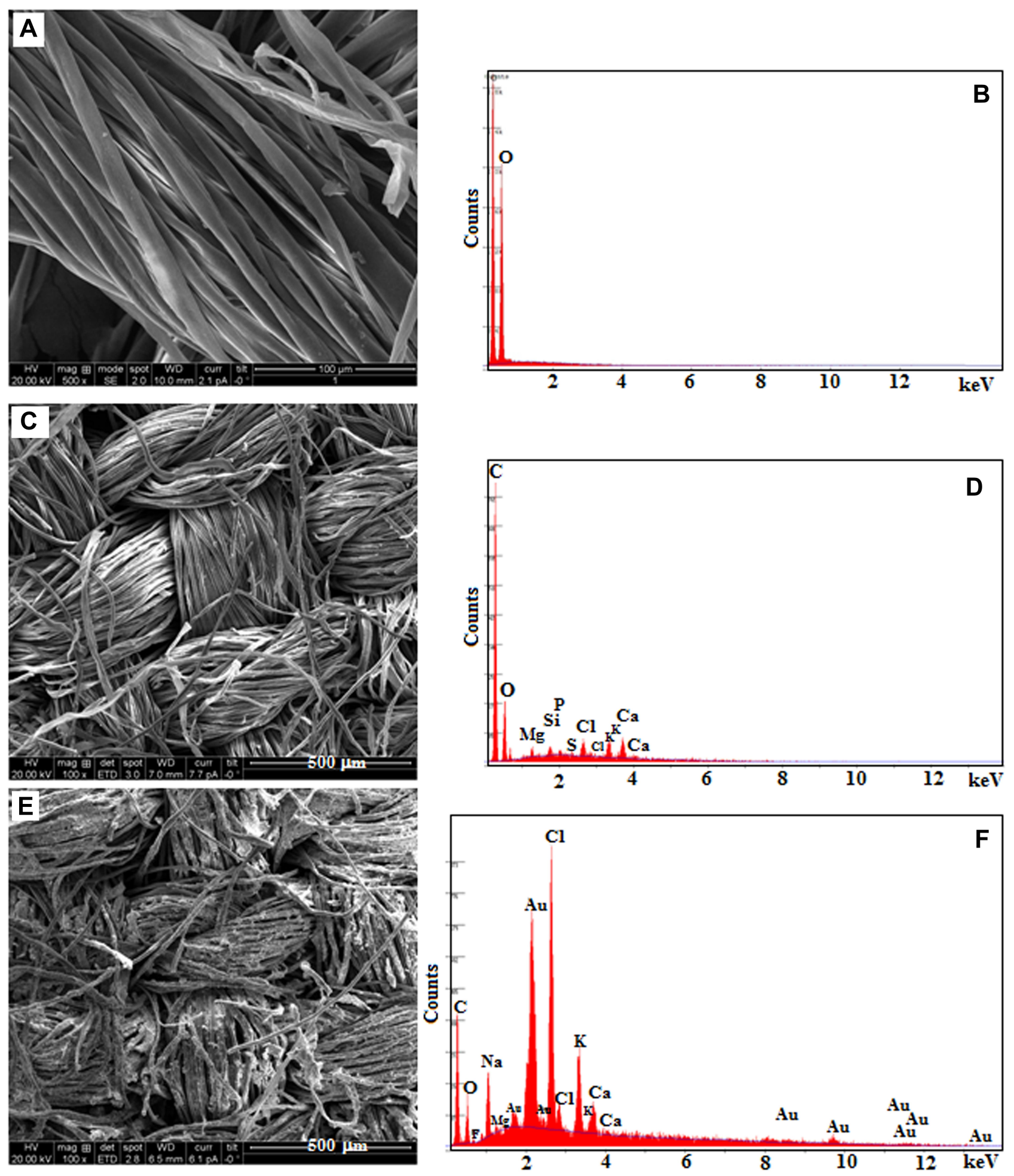

Figure 7 SEM with EDAX images of (A and $\mathbf{B})$ uncoated cotton, (C and $\mathbf{D})$ neat extract-coated cotton and (E and $\mathbf{F})$ extract containing AuNPs-coated cotton. Abbreviations: SEM, scanning electron microscope; EDAX, energy dispersive analysis of X-rays; AuNPs, gold nanoparticles.

values observed in the reported article (ZOI $=29 \mathrm{~mm}$ and $30 \mathrm{~mm}$ ). Moreover, we have used unique gold NPs from aqueous extracts of Acalypha indica and obtained the best antibacterial activity against $S$. epidermidis with ZOI of $31 \mathrm{~mm}$ diameter, which is very significant and not reported in the literature. 


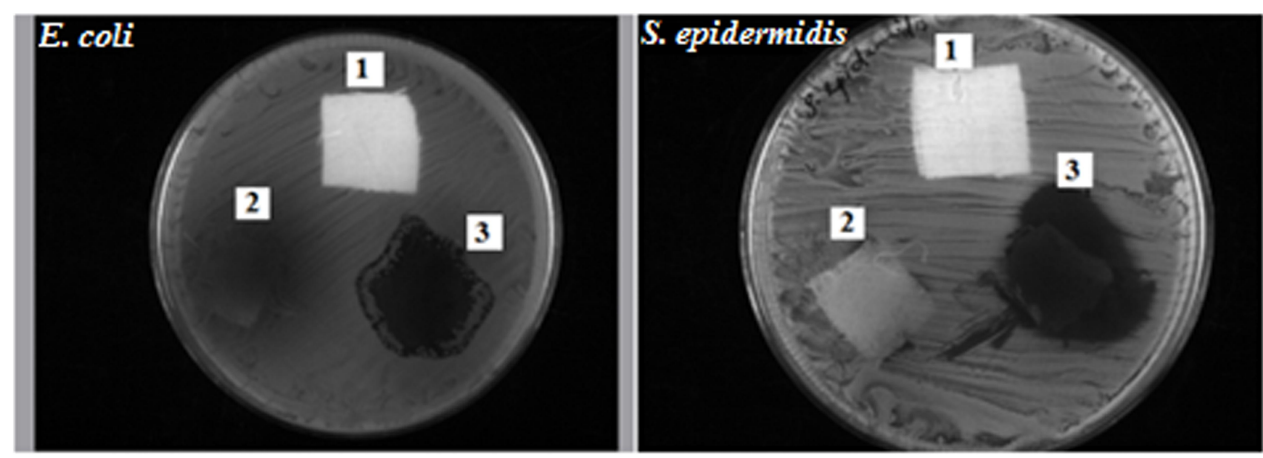

Figure 8 Antibacterial efficiency of AuNPs synthesized using Acalypha indica leaf extract prepared at $100{ }^{\circ} \mathrm{C}:(1)$ Uncoated cotton, (2) Extract-coated cotton, (3) Extract containing AuNPs-coated cotton.

Abbreviation: AuNPs, gold nanoparticles.

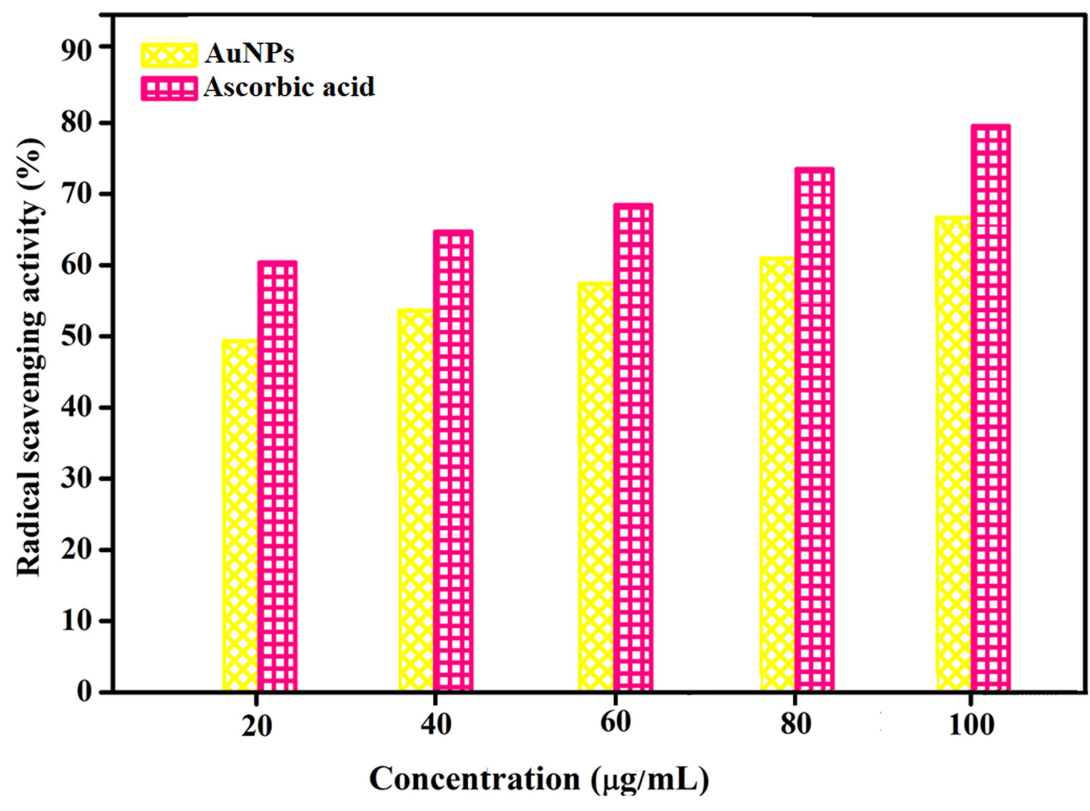

Figure 9 In vitro antioxidant activity of extract containing AuNPs.

Abbreviation: AuNPs, gold nanoparticles.

\section{In vitro Evaluation of the Antioxidant Activity}

The free radical scavenging ability of the extract containing AuNPs is presented in Figure 9. The result showed that the extract containing AuNPs has effective antioxidant activity against DPPH free radical scavenging. The maximum antioxidant activity of the extract containing AuNPs is found to be $80 \%$ at $100 \mu \mathrm{g} / \mathrm{mL}$. The potent free radical scavenging property of the nanoparticles is noticed at $\mathrm{IC}_{50}$ value $16.25 \mu \mathrm{g} / \mathrm{mL}$. This may be due to their ability to donate electrons or hydrogen ions to DPPH free radicals to neutralize them. When the concentration is increased, radical scavenging is also increased proportionally. Moreover, the plant contains most of the bioactive compounds which have been attributed to their antioxidant ability. ${ }^{73}$ Our antioxidant activity result was found to be different from literature reports involving different nanoparticles deduced from other medicinal plants. ${ }^{44,45}$ In the first study, authors conducted the antioxidant activity of copper NPs of Falcaria vulgaris leaf extract and obtained the activity at $\mathrm{IC}_{50}$ value of $190 \mu \mathrm{g} / \mathrm{mL}$, which indicated less antioxidant activity. Comparatively, we have obtained highly potent and 10 times greater antioxidant activity than the literature report. ${ }^{38}$ The same research group in another study reported the antioxidant activity at $\mathrm{IC}_{50}$ value $193 \mu \mathrm{g} / \mathrm{mL}$ for silver NPs obtained using A. saralicum aqueous extract. We have obtained greater potency at $\mathrm{IC}_{50}$ value $16.25 \mu \mathrm{g} / \mathrm{mL}$ for 
A
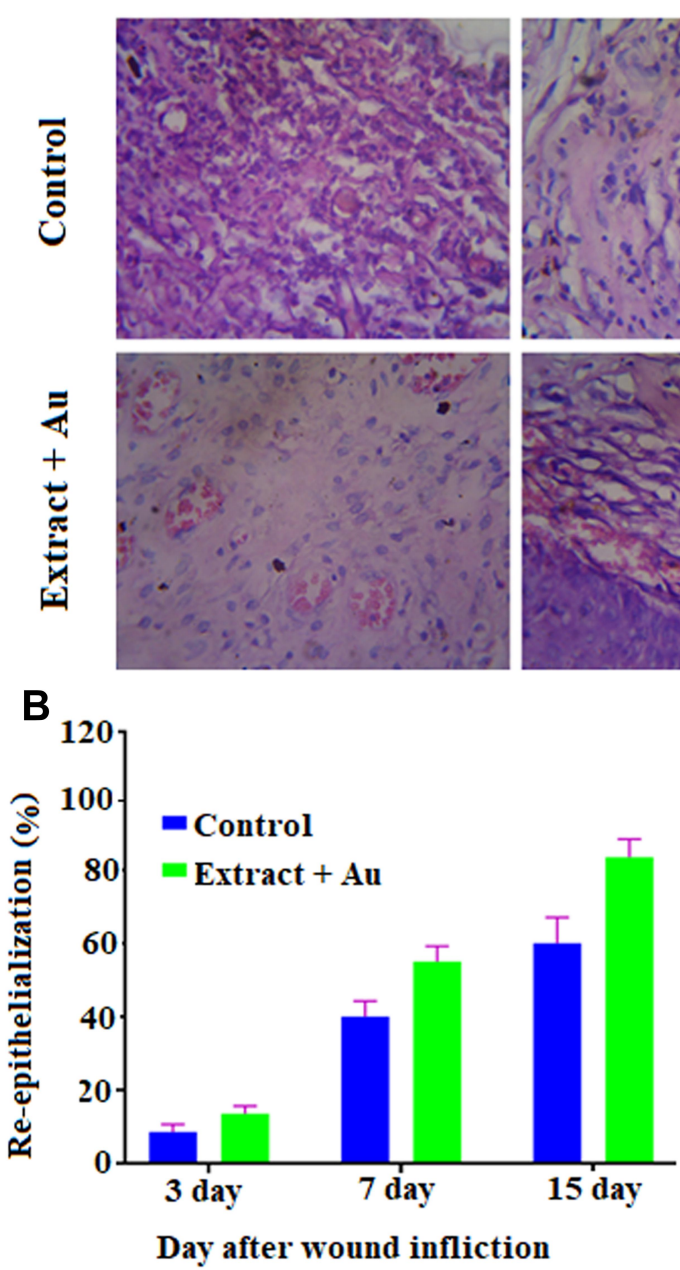

7 day
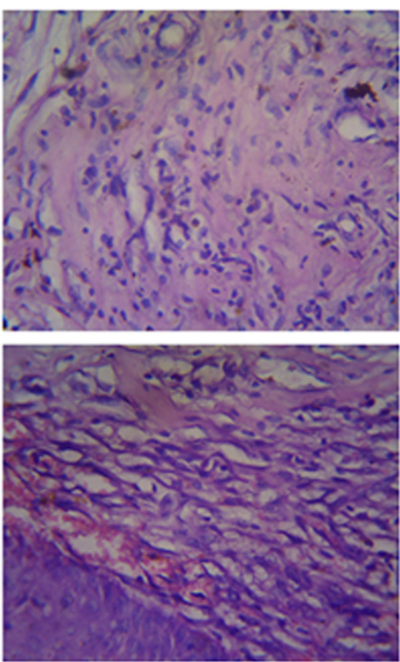

C

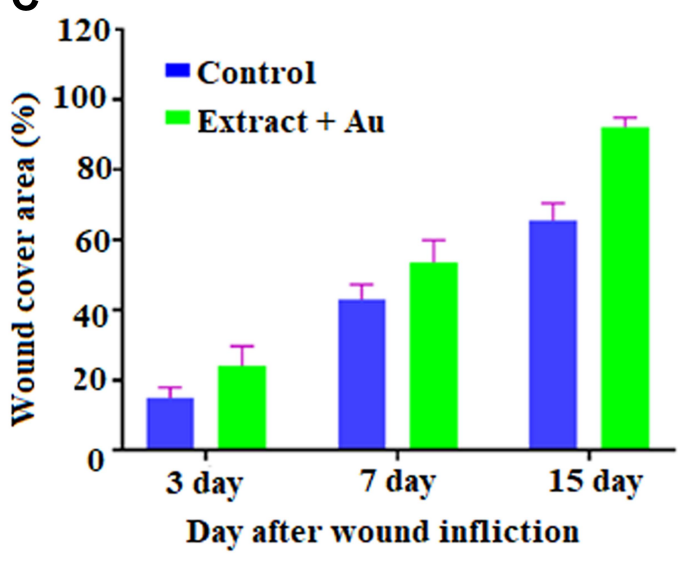

Figure 10 (A) Hematoxylin and Eosin stained microscopic images of regenerated structure of incised wounds on different days (3, 7 and I5) for treated with control, and extract containing AuNPs at 10x magnifications (scale bar $100 \mu \mathrm{m}$ ); (B) Histogram of re-epithelialization (in \%); (C) Histogram of wound-cover area (in \%). Abbreviation: AuNPs, gold nanoparticles.

gold NPs derived from aqueous extract of Acalypha indica which is unique, significant and the best antioxidant activity result than the literature report. ${ }^{39}$

\section{In vivo Evaluation of the Wound-Healing Activity}

The in vivo wound-healing activity was conducted through observing H\&E and MTS stained microscopic images at different day intervals (day 2, day 7 and day 15) is displayed in Figures 9 and 10, respectively. From both stains, collagen deposition, tissue re-epithelialization, mononuclear inflammatory infiltration, and neo-angiogenesis are determined. In H\&E stained images of the control sample, re-epithelialization is started along with newly-formed granulation tissue and no tissue regeneration is noticed
(Figure 10). In addition, the wound exhibited unfavorable healing conditions with a larger size open, which has not been covered by the re-epithelialization process. At the time of 2 days, the extract containing AuNPs treated in the group exhibited slightly improved re-epithelialization along with a smaller size of the open wound and little inflammatory cells when compared to the control group. Further, a larger number of red blood vessels were observed, which was characterized by a bigger vessel lumen filled with red blood cells. At the time of 7 days, the treated group exhibited thicker re-epithelialization layer together with improved neovascularization and a higher healing process is observed when compared to control. Moreover, a larger number of red blood vessels have appeared. In 15 days, the wound area is completely 
A

2 day

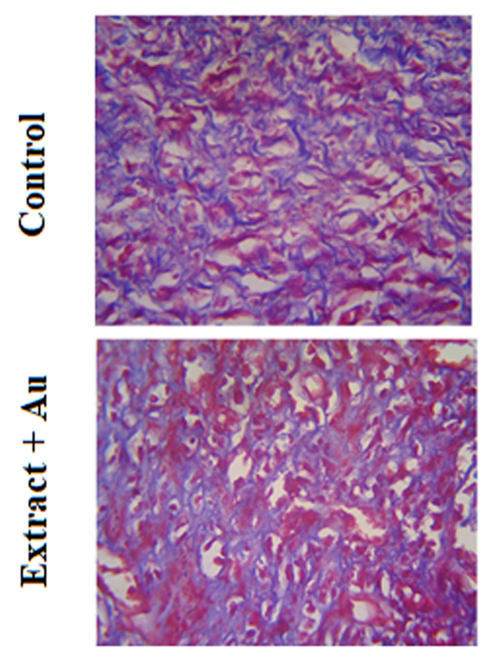

7 day
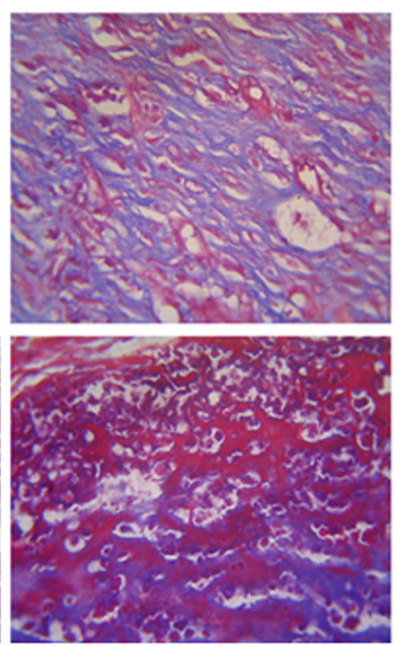

15 day
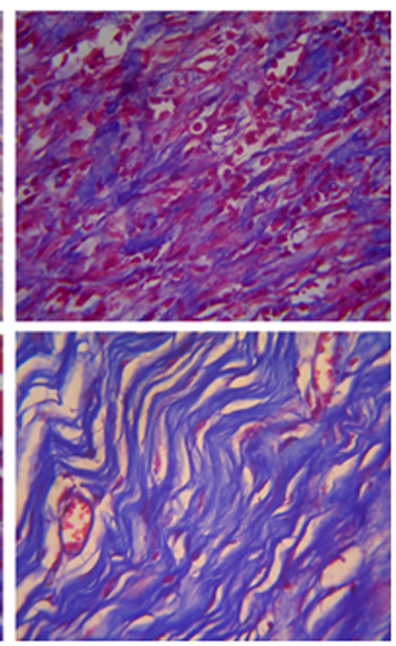

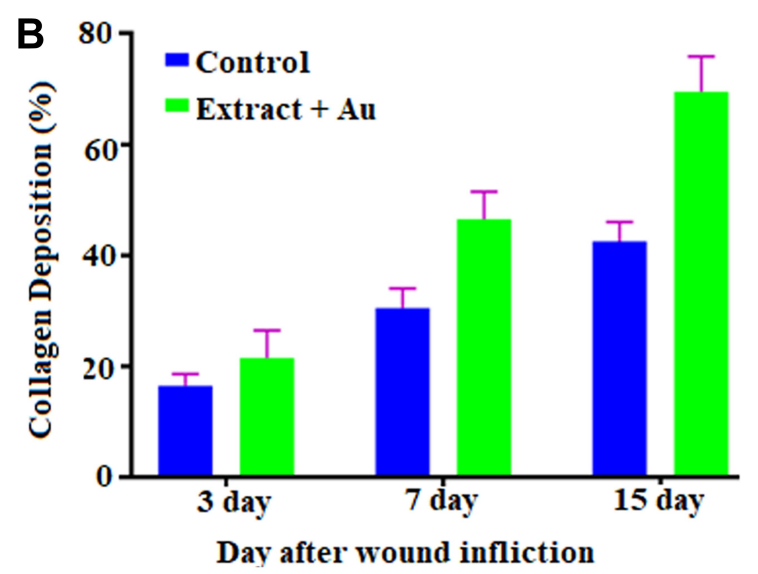

Figure I I (A) Masson's Trichrome staining images of regenerated structure of incised wounds in different days (3, 7 and I5) for treated with control, and extract containing AuNPs at 10x magnifications (scale bar $100 \mu \mathrm{m}$ ); (B) Histogram of collagen deposition (in \%).

Abbreviation: AuNPs, gold nanoparticles.

re-epithelialized due to the presence of different morphologies such as spherical, needle and triangle nanoparticles. The re-epithelialization layer is fully covered by nanoparticles on the wound site area and also collagen filled in the scar tissue when compared with the control group. As observed in the images, amongst various morphologies, spherical morphology has higher particles which show complete re-epithelialization. The deposition of collagen is regular than other groups, which specify neo-tissue formation enhanced by the nanoparticle-mediated collagen (Figure 11). The results revealed that the extract containing AuNPs accelerated the ending of the inflammatory stage, forming of blood vessels and remodeling of the collagen matrix, resulting in faster skin regeneration and improved healing of wounds than the control group..$^{35,74,75}$ AuNPs have endogenous antibacterial properties that are also helping to reduce the wound healing through inflammatory and hemostasis phases. ${ }^{76}$ AuNPs possibly accelerate the wound-healing activity through different mechanisms such as angiogenesis pathway, altering the membrane potential, inhibiting enzyme ATP synthase, triggering the optimum intracellular ROS, eventually leading to hampered energy metabolism and wound healing. Our results are significant while comparing with other reported studies involving copper NPs derived from Falcaria vulgaris leaf extract.

\section{Conclusion}

Herein, we reported the simple, facile, and eco-friendly greener synthesis of AuNPs from Acalypha indica extract and analyzed using sophisticated analytical methods. UVvisible spectroscopy, XRD analysis, HPLC analysis, and 
FT-IR techniques confirmed the synthesized gold nanoparticles. Further, FE-SEM and HR-TEM analyses established the size, shape and characterization of the synthesized gold nanoparticles. The promising antibacterial activity, antioxidant, free radical scavenging, and wound-healing properties of phyto-engineered gold nanoparticles are suggested for their potential therapeutic applications, which may be further extended to the textile technology as well.

\section{Acknowledgments}

Authors thankfully acknowledge the UGC-Innovative [No. F. 14-13/2013 (Inno/ASIST)], DST-FIST [SR/FST/LSI667/2016(C)], DST PURSE [SR/PURSE Phase 2/38 (G)], and MHRD-RUSA 2.0 [F.24/51/2014-U, Policy (TNMulti-Gen), Dept. of Edn. Govt. of India] for the financial supports and infrastructure facilities. One of the authors (CB) wish to thank Faculty of Pharmacy and Philadelphia University-Jordan for the research funding (No. 467/34/100 PU).

\section{Disclosure}

The authors report no conflicts of interest in this work.

\section{References}

1. Khan ST, Musarrat J, Al-Khedhairy AA. Countering drug resistance, infectious diseases, and sepsis using metal and metal oxides nanoparticles: current status. Colloids Surf B Biointerfaces. 2016;146:70-83. doi:10.1016/j.colsurfb.2016.05.046

2. Ambrogi V, Pietrella D, Donnadio A, et al. Biocompatible alginate silica supported silver nanoparticles composite films for wound dressing with antibiofilm activity. Mater Sci Eng. 2020;112:110863. doi:10.1016/j.msec.2020.110863

3. Boomi P, Prabu H. Synthesis, characterization and antibacterial analysis of polyaniline/Au-Pd nanocomposite. Colloids Surf a Physicochem Eng Asp. 2013;429:51-59. doi:10.1016/j.colsurfa.2013.03.053

4. Schrofel A, Kratosova G, Safarík I, Safarikova M, Raska I, Shor L. Applications of biosynthesized metallic nanoparticles - a review. Acta Biomater. 2014;10:4023-4042. doi:10.1016/j.actbio.2014.05.022

5. Maghimaa M, Alharbi SA. Green synthesis of silver nanoparticles from Curcuma longa L. and coating on the cotton fabrics for antimicrobial applications and wound healing activity. $J$ Photochem Photobiol B. 2020;204:111806. doi:10.1016/j.jphotobiol.2020.111806

6. Zayed MF, Eisa WH. Phoenix dactylifera L. leaf extract phytosynthesized gold nanoparticles; controlled synthesis and catalytic activity. Spectrochim Acta A Mol Biomol Spectrosc. 2014;121:238. doi:10.1016/j.saa.2013.10.092

7. Bankura K, Maity D, Mollick M, et al. Antibacterial activity of Ag-Au alloy NPs and chemical sensor property of Au NPs synthesized by dextran. Carbohydr Polym. 2014;107:151-157. doi:10.1016/j. carbpol.2014.02.047

8. Emmanuel R, Karuppiah C, Chen S, Palanisamy S, Padmavathy S, Prakash P. Green synthesis of gold nanoparticles for trace level detection of a hazardous pollutant (nitrobenzene) causing Methemoglobinaemia. $J$ Hazard Mater. 2014;279:117-124. doi:10.1016/j.jhazmat.2014.06.066
9. Pallela PNV, Ummey S, Ruddaraju LK, et al. Antibacterial efficacy of green synthesized $\alpha-\mathrm{Fe}_{2} \mathrm{O}_{3}$ nanoparticles using Sida cordifolia plant extract. Heliyon. 2019;5(11):e02765. doi:10.1016/j.heliyon.2019.e02765

10. Rajoka MSR, Mehwish HM, Zhang H, et al. Antibacterial and antioxidant activity of exopolysaccharide mediated silver nanoparticle synthesized by Lactobacillus brevis isolated from Chinese koumiss. Colloids Surface B. 2020;186:110734. doi:10.1016/j.colsurfb.2019.110734

11. Singh J, Kapoor N, Verma A. A study to evaluate the effect of phytosilver nanoparticles synthesized using Oxalis stricta plant leaf extract on extracellular fungal amylase and cellulose. Mater Today Proc. 2019;18:1342-1350. doi:10.1016/j.matpr.2019.06.599

12. Ahn E-Y, Jin H, Park Y. Assessing the antioxidant, cytotoxic, apoptotic and wound healing properties of silver nanoparticles greensynthesized by plant extracts. Mater Sci Eng C. 2019;101:204-216.

13. Yusefi M, Shameli K, Ali RR, Pang S-W, Teow S-Y. Evaluating anticancer activity of plant-mediated synthesized iron oxide nanoparticles using Punica Granatum fruit peel extract. J Mol Struct. 2020;1204:127539. doi:10.1016/j.molstruc.2019.127539

14. El-Rafie H, El-Rafie M, Zahran M. Green synthesis of silver nanoparticles using polysaccharides extracted from marine macro algae. Carbohydr Polym. 2013;96:403-410. doi:10.1016/j.carbpol.2013.03.071

15. Ortiz-Benítez EA, Velazquez-Guadarrama N, Duran Figueroa NV, Quezada H, Olivares-Trejo JJ. Antibacterial mechanism of gold nanoparticles on Streptococcus pneumoniae. Metallomics. 2019;11:1265-1276. doi:10.1039/C9MT00084D

16. Rajasekar P, Palanisamy S, Anjali R, et al. Cladophora fascicularis mediated silver nanoparticles: assessment of their antibacterial activity against Aeromonas hydrophila. J Cluster Sci. 2020;31:673-683. doi:10.1007/s10876-019-01674-w

17. Anand K, Rajamanikandan R, Sharma AS, et al. Human serum albumin interaction, in silico and anticancer evaluation of PineGold nanoparticles. Process Biochem. 2020;89:98-109.

18. Joseph S, Mathew B. Microwave assisted facile green synthesis of silver and gold nanocatalysts using the leaf extract of Aerva Lanata. Spectrochim Acta A Mol Biomol Spectrosc. 2015;136:1371-1379. doi:10.1016/j.saa.2014.10.023

19. Basavegowda N, Idhayadhulla A, Lee Y. Preparation of Au and Ag nanoparticles using Artemisia annua and their in vitro antibacterial and tyrosinase inhibitory activities. Mater Sci Eng C. 2014;43:58-64. doi:10.1016/j.msec.2014.06.043

20. Nasrollahzadeh M, Sajadi S, Maham M. Green synthesis of palladium nanoparticles using Hippophae rhamnoides Linn leaf extract and their catalytic activity for the Suzuki-Miyaura coupling in water. $J$ Mol Catal a Chem. 2015;396:297-303. doi:10.1016/j. molcata.2014.10.019

21. Guo M, Li W, Yang F, Liu H. Controllable biosynthesis of gold nanoparticles from a Eucommia ulmoides bark aqueous extract Mingxia. Spectrochim Acta A Mol Biomol Spectrosc. 2015;142:7379. doi:10.1016/j.saa.2015.01.109

22. Begum NA, Mondal S, Basu S, Laskar RA, Mandal D. Biogenic synthesis of $\mathrm{Au}$ and $\mathrm{Ag}$ nanoparticles using aqueous solutions of Black Tea leaf extracts. Colloids Surf B Biointerfaces. 2009;71:113-118. doi:10.1016/j.colsurfb.2009.01.012

23. Isaac RS, Sakthivel G, Murthy C. Green synthesis of gold and silver nanoparticles using Averrhoa bilimbi fruit extract. J Nanotechnol. 2013;2013:1-6. doi:10.1155/2013/906592

24. Ahmed KB, Swetha S, Sivasubramanian A, Veerappan G, Veerappan A. Preparation of gold nanoparticles using Salicornia brachiata plant extract and evaluation of catalytic and antibacterial activity. Spectrochim Acta A Mol Biomol Spectrosc. 2014;130:54-58. doi:10.1016/j.saa.2014.03.070

25. Mollick MMR, Bhowmick B, Mondal D, et al. Anticancer (in vitro) and antimicrobial effect of gold nanoparticles synthesized using Abelmoschus esculentus (L.) pulp extract via a green route. RSC Adv. 2014;4:37838-37848. doi:10.1039/C4RA07285E 
26. Khalil MM, Ismail EH, El-Magdoub F. Biosynthesis of Au nanoparticles using olive leaf extract. Arabian J Chem. 2012;5(4):431-437. doi:10.1016/j.arabjc.2010.11.011

27. Abbasi T, Anuradha J, Ganaie SU, Abbasi SA. Gainful utilization of the highly intransigent weed ipomoea in the synthesis of gold nanoparticles. J King Saud Univ Sci. 2015;27:15-22. doi:10.1016/j. jksus.2014.04.001

28. Franco-Romano M, Gil MLA, Palacios-Santander JM, et al. Sonosynthesis of gold nanoparticles from a geranium leaf extract. Ultrason Sonochem. 2014;21:1570-1577. doi:10.1016/j.ultsonch.2014. 01.017

29. Rajeshkumar S, Menon S, Venkat Kumar S, et al. Antibacterial and antioxidant potential of biosynthesized copper nanoparticles mediated through Cissus arnotiana plant extract. J Photochem Photobiol B. 2019;197:111531. doi:10.1016/j.jphotobiol.2019.111531

30. Abdel-Raouf N, Al-Enazi NM, Ibraheem IB. Green biosynthesis of gold nanoparticles using Galaxaura elongata and characterization of their antibacterial activity. Arabian J Chem. 2017;10:S3029-39. doi:10.1016/j.arabjc.2013.11.044

31. Kuppusamy P, Yusoff MM, Maniam GP, Govindan N. Biosynthesis of metallic nanoparticles using plant derivatives and their new avenues in pharmacological applications - an updated report. Saudi Pharm J. 2016;24:473-484. doi:10.1016/j.jsps.2014.11.013

32. Boomi P, Ganesan RM, Poorani G, Prabu HG, Ravikumar S, Jeyakanthan J. Biological synergy of greener gold nanoparticles by using Coleus aromaticus leaf extract. Mater Sci Eng C. 2019;99:202210. doi:10.1016/j.msec.2019.01.105

33. Ponnanikajamideen M, Rajeshkumar S, Vanaja M, Annadurai G. In vivo type 2 diabetes and wound-healing effects of antioxidant gold nanoparticles synthesized using the insulin plant Chamaecostus cuspidatus in albino rats. Canadian J Diabetes. 2019;43:82-89. doi:10.1016/j.jcjd.2018.05.006

34. Arafa MG, El-Kased RF, Elmazar MM. Thermoresponsive gels containing gold nanoparticles as smart antibacterial and wound healing agents. Sci Rep. 2018;8:13674. doi:10.1038/s41598-01831895-4

35. Hajialyani M, Tewari D, Sobarzo-Sánchez E, Nabavi SM, Farzaei MH, Abdollahi M. Natural product-based nanomedicines for wound healing purposes: therapeutic targets and drug delivery systems. Int $J$ Nanomedicine. 2018;13:5023-5043. doi:10.2147/ IJN.S174072

36. Mihai MM, Dima MB, Dima B, Holban AM. Nanomaterials for wound healing and infection control. Materials (Basel). 2019;12:2176. doi:10.3390/ma12132176

37. Marza S, Magyari K. Skin wound regeneration with bioactive glassgold nanoparticles ointment. Biomed Mater. 2019;14:025011. doi:10.1088/1748-605X/aafd7d

38. Zangeneh MM, Ghaneialvar H, Akbaribazm M, et al. Novel synthesis of Falcaria vulgaris leaf extract conjugated copper nanoparticles with potent cytotoxicity, antioxidant, antifungal, antibacterial, and cutaneous wound healing activities under in vitro and in vivo condition. $J$ Photochem Photobiol B. 2019;197:111556.

39. Zangeneh MM, Bovandi S, Gharehyakheh S, Zangeneh A, Irani P. Green synthesis and chemical characterization of silver nanoparticles obtained using Allium saralicum aqueous extract and survey of in vitro antioxidant, cytotoxic, antibacterial and antifungal properties. Appl Organometal Chem. 2019;33:e4961.

40. Nateghi MR, Shateri-Khalilabad M. Silver nanowire-functionalized cotton fabric. Carbohydr Polym. 2015;117:160-168. doi:10.1016/j. carbpol.2014.09.057

41. Yazhini KB, Prabu HG. Antibacterial activity of cotton coated with $\mathrm{ZnO}$ and ZnO-CNT composites. Appl Biochem Biotechnol. 2015;175:85-92. doi:10.1007/s12010-014-1257-8

42. Nabil B, El-Ahmida A, Christine C, Julien V, Abdelkrim A. Polyfunctional cotton fabrics with catalytic activity and antibacterial capacity. Chem Eng J. 2018;351:328-339.
43. Liu H, Lv M, Deng B, et al. Laundering durable antibacterial cotton fabrics grafted with pomegranate-shaped polymer wrapped in silver nanoparticle aggregations. Sci Rep. 2014;4:5920. doi:10.1038/ srep05920

44. Boomi P, Poorani G, Selvam S, et al. Green biosynthesis of gold nanoparticles using Croton sparsiflorus leaves extract and evaluation of UV protection, antibacterial and anticancer applications. Appl Organometal Chem. 2020;34:E5574. doi:10.1002/aoc.5574

45. Shahid-ul-Islam BS, Mohammad BF. Silver nanomaterials as future colorants and potential antimicrobial agents for natural and synthetic textile materials. RSC Adv. 2016;6:44232. doi:10.1039/C6RA05799C

46. Shaheen TI, Abd El Aty AA. In-situ green myco-synthesis of silver nanoparticles onto cotton fabrics for broad spectrum antimicrobial activity. Int $J$ Biol Macromol. 2018;118(Part):B:2121-30. doi:10.1016/j.ijbiomac.2018.07.062

47. Khan I, Saeed K, Khan I. Nanoparticles: properties, applications and toxicities. Arabian J Chem. 2019;12:908-993. doi:10.1016/j. arabjc.2017.05.011

48. Nouf Mahmoud NN, Hikmat S, Abu Ghith D, et al. Gold nanoparticles loaded into polymeric hydrogel for wound healing in rats: effect of nanoparticles' shape and surface modification. Int $J$ Pharm. 2019;565:174-186. doi:10.1016/j.ijpharm.2019.05.016

49. Pannerselvam B, Dharmalingam Jothinathan MK, Rajenderan M, et al. An in vitro study on the burn wound healing activity of cotton fabrics incorporated with phytosynthesized silver nanoparticles in male Wistar albino rats. Eur J Pharm Sci. 2017;100:187-196.

50. Naik R, Nemani H, Pothania S, et al. Obesity-alleviating capabilities of Acalypha indica, Pergulari ademia and Tinospora cardifolia leaves methanolic extracts in WNIN/GR-Ob rats. $J$ Nutr Intermed Metab. 2019;16:100090. doi:10.1016/j.jnim.2019.02.001

51. Rajendran R, Balakumar C, Ahammed HA, Jayakumar S, Vaideki K, Rajesh EM. Use of zinc oxide nano particles for production of antimicrobial textiles. Int J Eng Sci Technol. 2010;2:202.

52. Karthik S, Suriyaprabha R, Vinoth M, et al. Larvicidal, super hydrophobic and antibacterial properties of herbal nanoparticles from Acalypha indica for biomedical applications. RSC Adv. 2017;7:41763-41770.

53. Dobson J. Gene therapy progress and prospects: magnetic nanoparticle-based gene delivery. Gene Ther. 2006;13:283-287. doi:10.1038/ sj.gt. 3302720

54. Saxena A, Tripathi RM, Zafar F, Singh P. Green synthesis of silver nanoparticles using aqueous solution of Ficus benghalensis leaf extract and characterization of their antibacterial activity. Mater Lett. 2012;67:91-94.

55. Braca A, De Tommasi N, Di Bari L, Pizza C, Politi M, Morelli I. Antioxidant principles from Bauhinia tarapotensis. J Nat Prod. 2001;64:892-895. doi:10.1021/np0100845

56. Sonamuthu J, Cai Y, Liu H, et al. MMP-9 responsive dipeptidetempted natural protein hydrogel-based wound dressings for accelerated healing action of infected diabetic wound. Int J Biol Macromol. 2019;19:S0141.

57. MubarakAli D, Thajuddin N, Jeganathan K, Gunasekaran M. Plant extract mediated synthesis of silver and gold nanoparticles and its antibacterial activity against clinically isolated pathogens. Colloids Surf $B$ Biointerfaces. 2011;85(2):360-365. doi:10.1016/j.colsurfb.2011.03.009

58. Boomi P, Poorani G, Palanisamy S, et al. Evaluation of antibacterial and anticancer potential of polyaniline-bimetal nanocomposites synthesized from chemical reduction method. J Cluster Sci. 2019;30:715-726.

59. Kanchi S, Kumar G, Lo AY, et al. Exploitation of de-oiled jatropha waste for gold nanoparticles synthesis: a green approach. Arabian $J$ Chem. 2018;11:247-255. doi:10.1016/j.arabjc.2014.08.006

60. Akula KK, Chandrasekaran B, Kaur M, Kulkarni SK. Development and validation of a specific RP-HPLC method for the estimation of $\gamma$ aminobutyric acid in rat brain tissue samples using benzoyl chloride derivatization and PDA detection. Acta Chromatogr. 2015;27:413433. doi:10.1556/AChrom.27.2015.3.2 
61. Balachandar R, Gurumoorthy P, Karmegam N, et al. Plant-mediated synthesis, characterization and bactericidal potential of emerging silver nanoparticles using stem extract of Phyllanthus pinnatus: a recent advance in phytonanotechnology. J Cluster Sci. 2019;30 (6):1481-1488. doi:10.1007/s10876-019-01591-y

62. Vidhya S, Narayanan BL, Malairajan P, et al. Analytical method development and validation for the quantitative estimation of cefditoren pivoxil in tablet formulation by RP-HPLC. Int J Drug Dev Res. 2012;4:5186.

63. Pandey S, Goswami GK, Nanda KK. Green synthesis of polysaccharide/gold nanoparticle nanocomposite: an efficient ammonia sensor. Carbohydr Polym. 2013;94:229-234. doi:10.1016/j.carbpol.2013. 01.009

64. Smitha SL, Philip D, Gopchandran KG. Green synthesis of gold nanoparticles using Cinnamomum zeylanicum leaf broth. Spectrochim Acta A Mol Biomol Spectrosc. 2009;74:735-739. doi:10.1016/j.saa.2009.08.007

65. Shankar SS, Rai A, Ahmad A, Sastry M. Rapid synthesis of Au, Ag, and bimetallic $\mathrm{Au}$ core-Ag shell nanoparticles using Neem (Azadirachta indica) leaf broth. $J$ Colloid Interface Sci. 2004;275:496-502. doi:10.1016/j.jcis.2004.03.003

66. Ullah N, Yasin S, Abro Z, Liu L, Wei Q. Mechanically robust and antimicrobial cotton fibers loaded with silver nanoparticles: synthesized via Chinese holly plant leaves. Int J Text Sci. 2014;3:1-5.

67. Sivakumar A, Murugan R, Sundaresan K, Periyasamy S. UV protection and self-cleaning finish for cotton fabric using metal oxide nanoparticles. Indian J Fibre Text Res. 2013;38:285-292.

68. Tao C. Antimicrobial activity and toxicity of gold nanoparticles: research progress, challenges and prospects. Lett Appl Microbiol. 2018;67:537-543. doi:10.1111/lam.13082

69. Makarov VV, Love AJ, Sinitsyna OV, et al. "Green" nanotechnologies: synthesis of metal nanoparticles using plants. Acta Naturae. 2014;6:35-44. doi:10.32607/20758251-2014-6-1-35-44
70. Hu J, Jian L, Gan L, Long M. Surface-modified graphene oxidebased cotton fabric by ion implantation for enhancing antibacterial activity. ACS Sustain Chem Eng. 2019;7:7686-7892. doi:10.1021/ acssuschemeng.8b06361

71. Hamouda T, Myc A, Donovan B, Shih AY, Reuter JD, Baker JR Jr. A novel surfactant nanoemulsion with a unique non-irritant topical antimicrobial activity against bacteria, enveloped viruses and fungi. Microbiol Res. 2001;156:1-7. doi:10.1078/0944-5013-00069

72. Sriram MI, Kanth SB, Kalishwaralal K, Gurunathan S. Antitumor activity of silver nanoparticles in Dalton's lymphoma ascites tumor model. Int $J$ Nanomedicine. 2010;5:753-762. doi:10.2147/IJN. S11727

73. Lee SY, Krishnamurthy S, Cho CW, Yun YS. Biosynthesis of gold nanoparticles using Ocimum sanctum extracts by solvents with different polarity. ACS Sustain Chem Eng. 2016;4(5):2651-2659. doi:10.1021/acssuschemeng.6b00161

74. Shankar S, Jaiswal L, Aparna RSL, Prasad RGV, Kumar GP, Manohara CM. Wound healing potential of green synthesized silver nanoparticles prepared from Lansium domesticum fruit peel extract. Mater Express. 2015;5(2):159-164. doi:10.1166/mex.2015.1225

75. Krychowiak M, Grinholc M, Banasiuk R, et al. Combination of silver nanoparticles and Drosera binata extract as a possible alternative for antibiotic treatment of burn wound infections caused by resistant Staphylococcus aureus. PLoS One. 2014;9:e115727. doi:10.1371/ journal.pone. 0115727

76. Nethi S, Sourav D, Patra C, Mukherjee S. Recent advances in inorganic nanomaterials for wound healing applications. Biomater Sci. 2019;7(7):2652-2674. doi:10.1039/C9BM00423
International Journal of Nanomedicine

\section{Publish your work in this journal}

The International Journal of Nanomedicine is an international, peerreviewed journal focusing on the application of nanotechnology in diagnostics, therapeutics, and drug delivery systems throughout the biomedical field. This journal is indexed on PubMed Central, MedLine, CAS, SciSearch ${ }^{\mathbb{}}$, Current Contents ${ }^{\mathbb{R}} /$ Clinical Medicine, $^{2}$

\section{Dovepress}

Journal Citation Reports/Science Edition, EMBase, Scopus and the Elsevier Bibliographic databases. The manuscript management system is completely online and includes a very quick and fair peer-review system, which is all easy to use. Visit http://www.dovepress.com/ testimonials.php to read real quotes from published authors. 